\title{
Potencial de vulnerabilidade natural de aquíferos à contaminação no quadrilátero ferrífero, Minas Gerais e sua relação com a atividade minerária de ouro
}

\section{Natural vulnerability of potential contamination to aquifers in the Iron Quadrangle, Minas Gerais and its relation to gold mining activity}

Samira da Conceição Sabadini Mestranda em Análise e Modelagem de Sistemas ambientais pela Universidade Federal de Minas Gerais (UFMG), Brasil samirasabadini@yahoo.com.br

Úrsula de Azevedo Ruchkys Doutora em Geologia. Professora do Departamento de Cartografia e do Programa de Pós-Graduação em Análise e Modelagem de Sistemas Ambientais do IGC/UFMG, Brasil tularuchkys@yahoo.com.br

Leila Nunes Menegasse Velásquez Doutora em Geologia. Professora do departamento de Geologia do IGC/UFMG, Brasil menegase@yahoo.com.br

Thiaggo de Castro Tayer Mestre em Geologia pela Universidade Federal de Minas Gerais (UFMG), Brasil thiaggotayer@hotmail.com

\begin{abstract}
Resumo
Este trabalho teve por objetivo analisar a vulnerabilidade natural dos aquíferos à contaminação na região do Quadrilátero Ferrífero $(\mathrm{QF})$, Minas Gerais e mostrar sua relação com as atividades de mineração de ouro. As minas de ouro ocorrem associadas ao Supergrupo Rio das Velhas em sua paragênese clássica de sulfetos. Foi aplicado o método GOD utilizando Sistemas de Informações Geográficas (SIG) considerando os seguintes parâmetros inerentes ao método: Tipologia do aquífero; Litologia; Profundidade do lençol freático ou nível d'água. A análise do mapa de vulnerabilidade gerado e sua correlação com a localização das minas de ouro permite afirmar que, embora a atividade de extração mineral tenha sido e ainda é significativa na região, os aquíferos apresentam baixa vulnerabilidade natural à contaminação. As áreas mais vulneráveis se encontram ao longo das serras onde atualmente se desenvolve, de forma expressiva, extração de minério de ferro. Em relação à localização das minas de ouro, a análise do mapa permite verificar que nas proximidades dessas minas a vulnerabilidade natural é baixa, o que diminui o risco de contaminação por drenagem ácida. A atividade minerária no Quadrilátero Ferrífero exercida desde os fins do século XVII representa uma fonte contínua de contaminação potencial sendo necessário o monitoramento da qualidade das águas subterrâneas e superficiais em longo prazo.
\end{abstract}

Palavras-chave: mineração; água subterrânea; método GOD; geoprocessamento.

\begin{abstract}
This study aimed to analyze the natural vulnerability of aquifers to contamination in the region of the Iron Quadrangle (QF), Minas Gerais and show its relation to gold mining activities. Gold mines occur associated with the Rio das Velhas Supergroup in his classic paragenesis sulphides. GOD method was applied using Geographic Information Systems (GIS) considering the following
\end{abstract}


parameters inherent in the method: Type aquifer; Lithology; Depth of the groundwater or water level. The analysis of the generated vulnerability map and its correlation with the location of the gold mines to suggest that, although the mining activity has been and is still significant in the region, aquifers have low natural vulnerability to contamination. The most vulnerable areas are along the mountains where he currently develops, significantly, iron ore extraction. Regarding the location of the gold mines, the map analysis shows that near these mines the natural vulnerability is low, which reduces the risk of contamination by acid mine drainage. The mining activity in the Iron Quadrangle exercised since the end of the seventeenth century represents a continuous source of potential contamination being necessary to monitor the quality of groundwater and surface water in the long term.

Keywords: mining; Groundwater; GOD method; GIS.

\section{INTRODUÇÃO}

A água, assim como os solos, as rochas, os fósseis e o relevo, é um dos elementos da geodiversidade e desempenha função fundamental para o desenvolvimento de praticamente todas as atividades humanas. Seu uso adequado e eficiente vem sendo considerado um dos grandes desafios para os órgãos gestores e para a comunidade científica na atualidade. Na promoção desses aspectos a compreensão relativa aos processos hidrológicos e a sua gestão é premente e deve integrar a água superficial e subterrânea simultaneamente em razão das variadas conexões hidráulicas entre esses dois mananciais, conforme destacam Paranhos \& Paiva (2008), Zanetti et al. (2009), Cutrim \& Campos (2010), Calil et al. (2012), dentre outros. Muradás et al. (2010) afirmam que mapeamento de vulnerabilidade à contaminação de aquíferos é um tema atual em planos de gestão ambiental sendo inclusive corroborado pela Resolução do CONAMA n 396/2008 que dispõe sobre o enquadramento, prevenção e controle de poluição das águas subterrâneas. Duijvenbooden \& Waegeningh (1987) definem a vulnerabilidade natural à poluição de águas subterrâneas como a sensibilidade da qualidade das águas subterrâneas a uma carga poluente em função apenas das características intrínsecas do aquífero. Para Krebs \& Possa (2008), a vulnerabilidade natural de um aquífero diz respeito à capacidade do meio físico de amortecer a carga de contaminantes nas águas subterrâneas. Para Frantz (2005), estudos sobre vulnerabilidade podem auxiliar na promoção da proteção destes recursos já que servem como orientadores no manejo e ocupação do uso dos solos. Vários estudos com abordagens e focos diferenciados envolvendo cartografia da vulnerabilidade vêm sendo desenvolvidos no Brasil: Martinez et al. (2008); Tavares et al. (2009); Vilar \& Ribeiro (2009); Maia \& Cruz (2011); Linhares et al. (2014).

Dentre as atividades que causam impactos e poluição aos recursos hídricos, destaca-se a atividade minerária, que tem como um dos principais problemas aqueles associados à drenagem ácida de mina. A drenagem ácida de mina é um efluente derivado da oxidação de sulfetos e alta concentração de metais pesados (alumínio, chumbo, ferro, manganês, zinco) e sulfatos. Esse efluente tem origem na extração do minério com consequente exposição do rejeito ao oxigênio e a 
água na superfície do solo (Bifano \& Souza, 2007). As águas ácidas provenientes desses ambientes tem alta capacidade de lixiviar metais pesados das rochas circundantes à área minerada, levando à degradação da qualidade dos recursos hídricos superficiais e subterrâneos adjacentes (Campaner \& Luiz-Silva, 2009; Abreu et al., 2012).

Objetivou-se, com este trabalho, modelar e analisar a vulnerabilidade natural dos aquíferos da região do Quadrilátero Ferrífero à contaminação utilizando o método GOD (Foster et al., 2002) com técnicas de geoprocessamento. O método GOD considera três parâmetros na análise da vulnerabilidade: o grau de confinamento do aquífero (Groundwater ocurrence - G); o tipo de rocha encontrada na zona não saturada (Overall litology of aquifer - O); e a profundidade da água no aquífero (Depth of level water-D).

\section{METODOLOGIA}

O Quadrilátero Ferrífero - QF localiza-se na porção centro-sudeste do Estado de Minas Gerais ocupando uma área aproximada de $7.000 \mathrm{Km}^{2}$. Geologicamente é formado por quatro grandes unidades litoestratigráficas arqueanas e paleoproterozóicas: (i) complexos metamórficos (Arqueano) composto por gnaisses, migmatitos e granitóide; (ii) Supergrupo Rio das Velhas (Arqueano) que forma uma sequência do tipo greenstone belt constituída por rochas vulcânicas e sedimentares; (iii) Supergrupo Minas (Paleoproterozoico), formado por metasedimentos, incluindo, dentre outros, conglomerados, quartzitos, itabiritos e dolomitos e (IV) o Grupo Itacolomi (Paleoproterozóico), composto de quartzitos e conglomerados. Segundo Ruchkys et al. (2012) destaca-se ainda a presença de rochas básicas e metabásicas que cortam as unidades litoestratigráficas e o Fanerozóico encontra-se restrito a pequenas bacias intramontanas cenozóicas, como as bacias do Gandarela e do Fonseca.

As numerosas ocorrências de minérios de ferro, manganês e ouro na região a caracterizam como uma das principais províncias metalogenéticas do mundo, com atividades minerárias desde finais do século XVII, com a exploração do ouro, intensificando-se no século XIX com a extração do ferro e do manganês, resultando em processos de degradação ambiental de longa data (Ruchkys, 2009; Ruchkys \& Machado, 2013).

Segundo Roeser \& Roeser (2010), as jazidas de ouro da região ocorrem em dois tipos: um associado às rochas quartzo-carbonáticas xistosas do Supergrupo Rio das Velhas em paragêneses clássicas com sulfetos de ferro, cobre e arsênio e outro em zonas de falhamentos em itabiritos do Supergrupo Minas. Borba et al. (2000), afirmam que a distribuição geográfica do arsênio nas rochas do QF guarda uma associação importante com as rochas auríferas sulfetadas do Supergrupo Rio das Velhas. 
Segundo Beato, Monsores \& Bertachinni (2006) os principais aquíferos do Quadrilátero Ferrífero estão em itabiritos e dolomitos onde são encontradas nascentes de até $500 \mathrm{~m}^{3} \mathrm{~h}^{-1}$ e poços tubulares com capacidades específicas de até $87 \mathrm{~m}^{3} \mathrm{~h}^{-1} \mathrm{~m}^{-1}$. Além dos aquíferos associados a itabiritos e a dolomitos, ocorrem os demais aquíferos: granular, quartzítico, formação ferrífera, xistoso, granito-gnáissico, e carbonático (Figura 1).

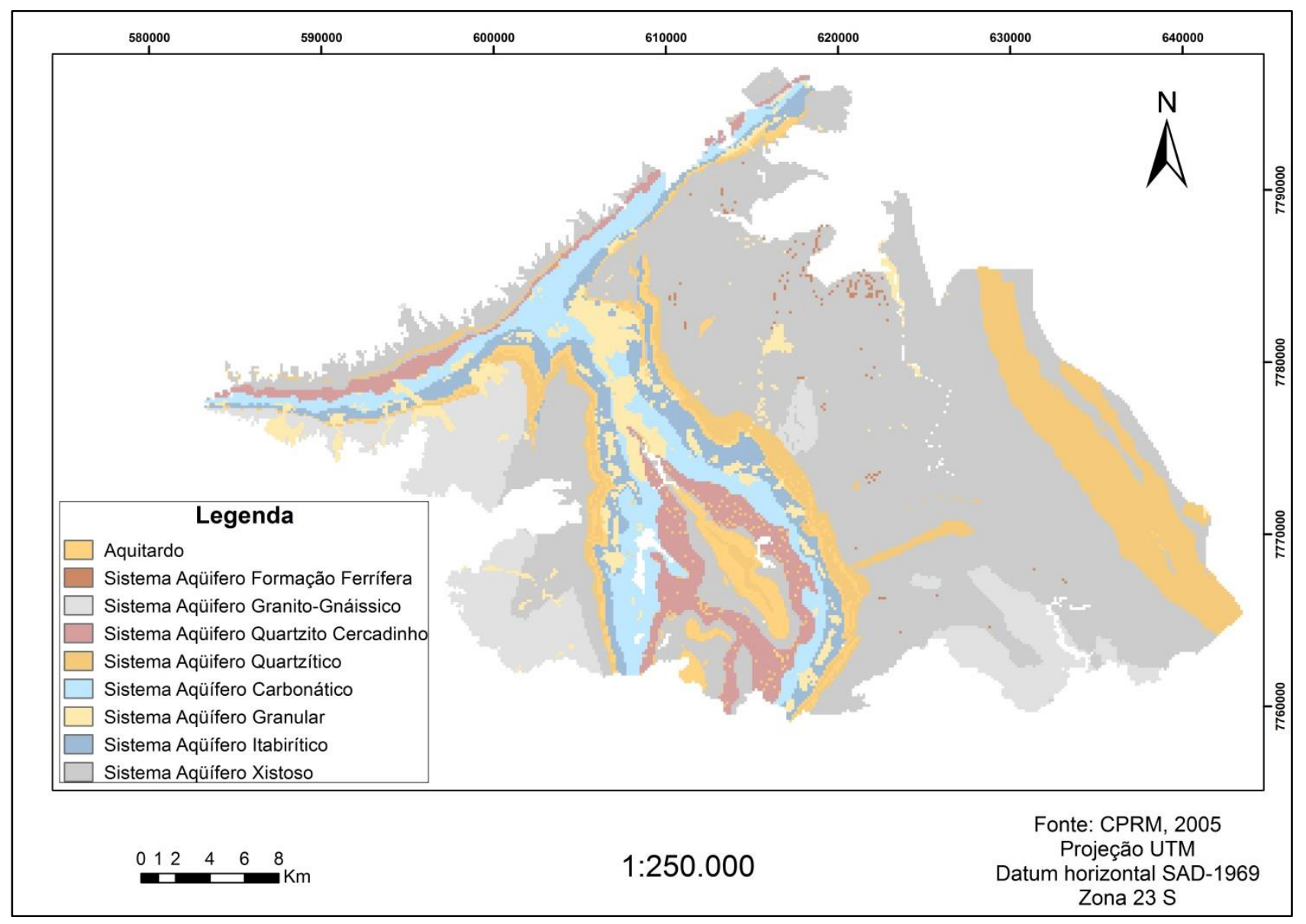

Figura 1 - Sistemas aquíferos da área de estudo.

Fonte: CPRM, 2005.

Cabe destacar que embora existam dois sistemas aquíferos associados a rochas ferruginosas (itabirítico e formação ferrífera), seu comportamento é diferenciado. Segundo Beato, Monsores \& Bertachinni (2006), enquanto o Sistema aquífero formação ferrífera está presente nos níveis interestratificados das rochas do Grupo Nova Lima e possui comportamento hidrodinâmico próximo do Sistema aquífero quartzítico, o Sistema aquífero itabirítico é o maior do Quadrilátero Ferrífero sendo formado, principalmente, por rochas da Formação Cauê do Grupo Itabira, pertencente ao Supergrupo Minas (o que lhe confere a denominação comum de aquífero Cauê).

Para litologia e hidrogeologia foram utilizadas as bases do mapeamento em escala 1: 50.000 e os dados de poços tubulares do Serviço Geológico do Brasil (CPRM, 2005). Nas plataformas Geobank e SIAGAS da CPRM foram obtidos os dados de ocorrência de minas de ouro (CPRM, acesso em 12 out. 2014), bem como os dados de profundidade do nível estático (CPRM, 
acesso em 13 Maio 2014) a partir do cadastro de poços tubulares. Foram utilizados os dados de 256 poços localizados na APA Sul. A profundidade da água no aquífero corresponde à profundidade que o contaminante terá que percorrer para alcançar a zona saturada do aquífero. A geração do mapa de profundidade de água no aquífero foi feita pela interpolação das profundidades de nível estático pelo método Inverse Distance Weighted (IDW). Para a interpolação foi utilizada a potência 2 e 12 pontos como vizinhança. O método IDW foi escolhido por considerar relevantes os pontos mais próximos, ou seja, a influência dos pontos vizinhos diminui com o aumento da distância entre eles.

Aplicaram-se aos três parâmetros os valores conforme proposto por Foster et al. (2002) que variam de zero a um, em que valores mais altos indicam maior vulnerabilidade natural (Figura 2) e o nível de vulnerabilidade resultante é obtido por meio do produto desses valores.

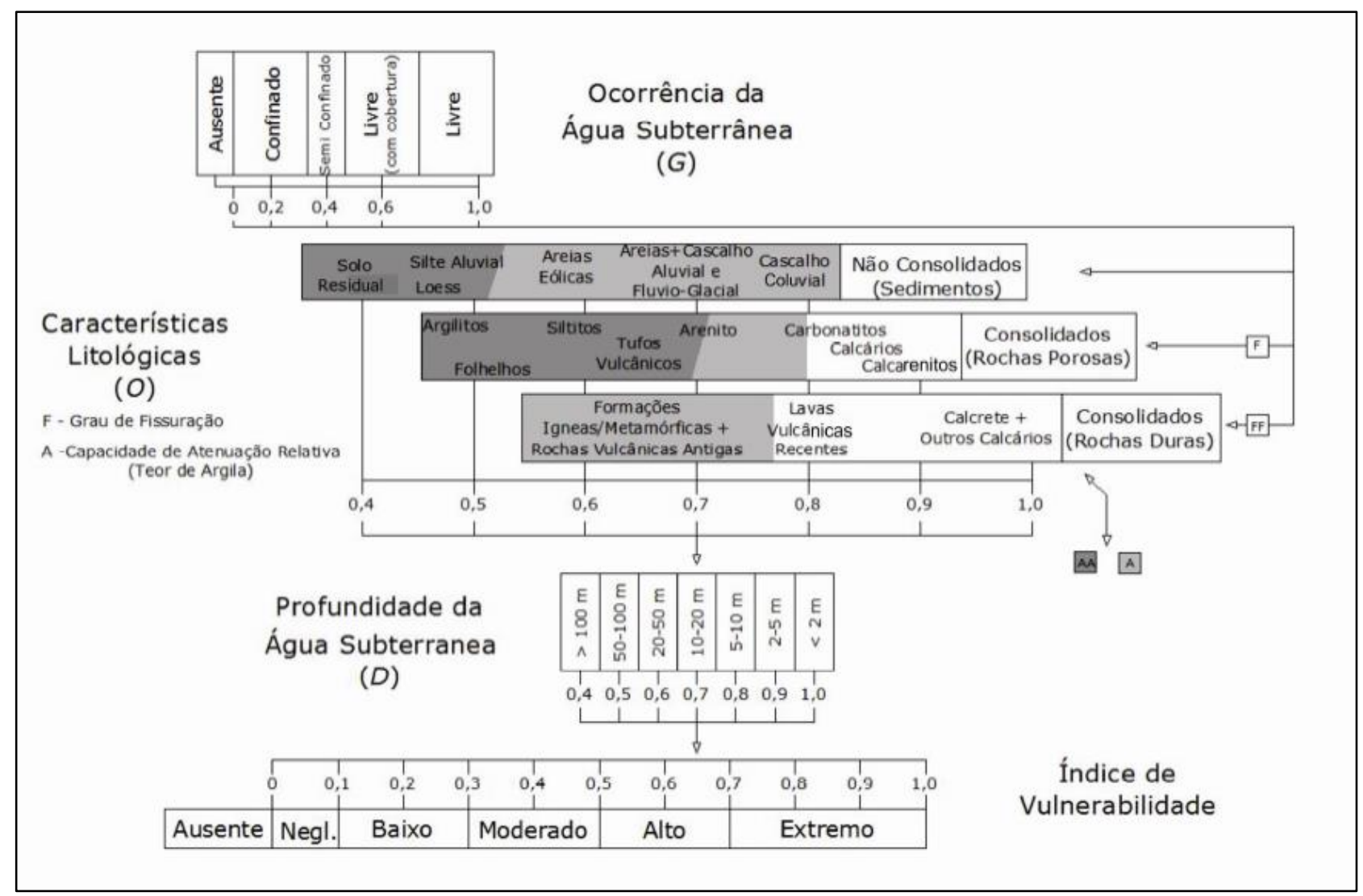

Figura 2 - Esquema de aplicação dos valores às camadas pelo método GOD. Fonte: Gonçalves (2012) adaptado de Foster \& Hirata (1987).

Com as bases e informações foram elaborados os mapas GOD e o mapa resultante de vulnerabilidade natural. 


\section{RESULTADOS E DISCUSSÃO}

\section{1. Índice G para Tipologia do Aquífero}

Foram identificados oito sistemas aquíferos e um aquitardo na área de estudo. As notas foram atribuídas de acordo com o tipo de aquífero, sendo a mais alta $(0,6)$ relacionada aos aquíferos livres com cobertura (Sistema aquífero granular e Sistema aquífero granito-gnáissico) e a mais baixa $(0,0)$ ao aquitardo já que sua estrutura praticamente não permite a passagem de água para maiores profundidades do solo. Os demais tipos de aquífero receberam as seguintes notas: Sistema Aquífero Quarzítico, Sistema Aquífero Itabirítico, Sistema Aquífero Xistoso, Sistema Aquífero Formação Ferrífera e Sistema Aquífero Carbonático (0,4); Sistema Aquífero Quartzito Cercadinho $(0,2)$.

A aplicação dos valores para o índice G gerou o mapa apresentado na Figura 3.

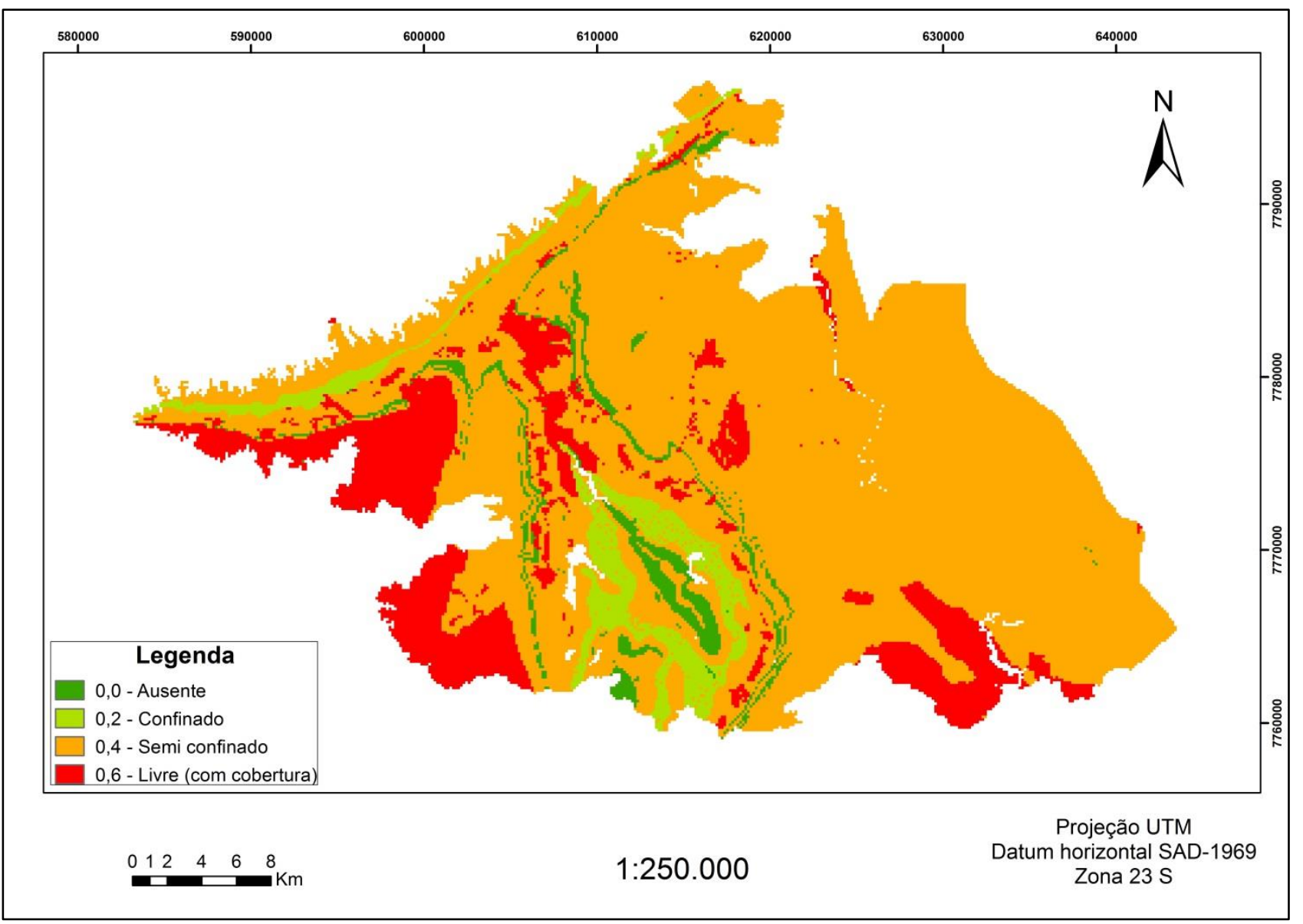

Figura 3 - Mapa de notas atribuídas à hidrogeologia da região de estudo.

Na descrição bibliográfica adotada, CPRM (2005), a maior parte dos sistemas aquíferos da área é de livre a confinados (sistemas: quartzítico, itabirítico, xistoso, formação ferrífera e carbonático), porém, sabe-se que o confinamento é pontual, por esse motivo, para esses aquíferos adotou-se a nota referente ao Sistema aquífero semi confinado. No caso do Sistema aquífero 
granito-gnáissico, classificado como livre a semi confinado, adotou-se a nota para Sistema aquífero livre optando-se por uma modelagem mais conservativa.

O tipo de Sistema aquífero mais susceptível à contaminação, dentre os presentes na área de estudo, é o aquífero livre (com cobertura) que não tem camada confinante, o que o torna mais vulnerável à contaminação. Este tipo de aquífero está presente, principalmente, na porção ocidental da área de estudo.

\section{2. Índice O para Litologia}

Foram consideradas sete classes de rochas. As notas foram atribuídas de acordo com a litologia, sendo as mais altas $(0,9$ e 1,0) atribuídas às rochas carbonáticas, em especial, mármores e dolomitos e as mais baixas $(0,4$ e 0,5$)$ atribuídas ao solo laterítico com níveis enriquecidos em óxidos de ferro, argila com grãos de quartzo, hematita e limonita, cascalhos, bauxita, argilito, arenito e linhito da seguinte forma: hematita compacta e pulvurulenta $(0,7)$; formação ferrífera, metachert, metabasaltos, xisto grafitoso $(0,7)$; itabirito dolomítico $(0,7)$; quartzo-sericita/moscovita xisto, quartzito e metaconglomerado $(0,7)$; Solo laterítico com níveis enriquecidos em óxidos de ferro $(0,4)$; Areia, silte e argila com matacões de formação ferrífera $(0,7)$; Filito e filito grafitoso $(0,6)$; Argila com grãos de quartzo, hematita e limonita, cascalhos, bauxita $(0,5)$; Filito $(0,6)$; Filito com intercalações de metachert (0,6); Esteatitos $(0,6)$; Gabro e diabásio (0,6); Filito dolomítico e argiloso e mármore (0,7); Filito e conglomerado (0,7); Quartzitos com intercalações de metaconglomerado (0,7); Quartzito e conglomerado (0,7); Xistos com intercalações de quartzito $(0,7)$; Quartzito, conglomerado e filito (0,7); Xisto metassedimentar, xisto metavulcânico e esteatitos (0,7); Mica-quartzo xisto, xisto grafitoso (0,7); Metagrauvaca, rocha calcissilicática, metaparaconglomerado, tremolita xisto $(0,7)$; Dolomito, itabirito dolomítico, filito dolomítico e argiloso (0,9); Matacões, calhaus e seixos de hematita em solo aluvial $(0,8)$; Fragmentos de itabirito em solo ferruginoso (0,8); Mármore (1,0); Formação Ferrífera $(0,7)$; Migmatitos e gnaisses $(0,6)$; Migmatitos com paleossomas anfibolíticos e epidosíticos $(0,6)$; Itabirito, itabirito dolomítico e corpos de hematita (0,7); Fragmentos de itabirito e hematita compacta, cimentados por limonita $(0,8)$; Granito e gnaisse granítico $(0,7)$; Quartzo-mica xisto, xisto carbonoso, formação ferrífera $(0,7)$; Rochas graníticas gnaissificadas $(0,6)$; Serpentinito, clorita-talco xisto, cloritito anfibolítico $(0,6)$; Metagabro $(0,7)$; Talco xisto ou clorita-talco xisto $(0,6)$; Plagioclásio-carbonato-quartzo-mica xisto (0,6); Quartzo-carbonato-clorita xisto (Lapa Seca) (0,7); Conglomerado (0,7); Argilito, arenito e linhito $(0,5)$; Serpentinitos, metagabros e esteatitos $(0,6)$; Dolomito $(0,9)$; Massas cuneiformes de dolomito $(0,9)$; Serpentinitos $(0,6)$; Metagabros (0,7); Quartzo-mica-clorita xisto, plagioclásioquartzo-mica xisto e xisto grafitoso $(0,7)$. 
A aplicação dos valores para o índice "O” gerou o mapa apresentado na Figura 4. As áreas mais vulneráveis estão ao longo das Serras do Curral, da Moeda e de Itabirito onde afloram rochas de composição carbonática associadas à Formação Gandarela.

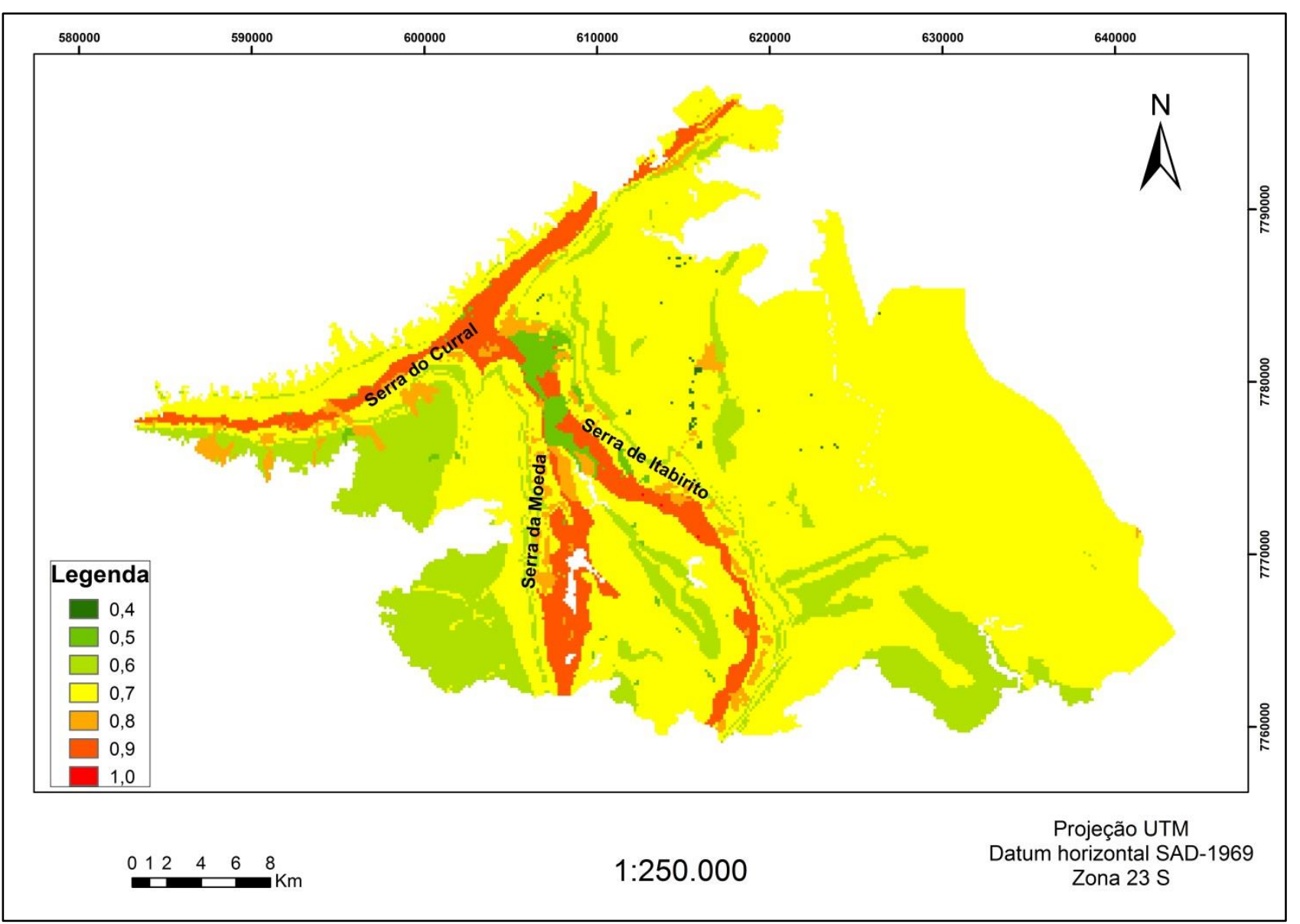

Figura 4 - Mapa de notas atribuídas à litologia da região de estudo.

\section{3. Índice D para Profundidade do Aquífero}

Foram consideradas sete classes de profundidade de água nos aquíferos. As notas mais altas foram atribuídas as menores profundidades que tornam o aquífero mais vulnerável (até $20 \mathrm{~m}$ ), as notas mais baixas foram atribuídas a maiores profundidades. As notas foram distribuídas de acordo com o nível freático da seguinte forma: Menor que $2 \mathrm{~m}(1,0)$; entre 2 e $5 \mathrm{~m}(0,9)$; entre 5 e $10 \mathrm{~m}(0,8)$; entre 10 e $20 \mathrm{~m}(0,7)$; entre 20 e $50 \mathrm{~m}(0,6)$; entre 50 e $100 \mathrm{~m}(0,5)$; maior que $100 \mathrm{~m}$ $(0,4)$. A aplicação dos valores para o índice D gerou o mapa apresentado na Figura 5.

As áreas mais vulneráveis estão localizadas onde há poços cadastrados. Provavelmente, a distribuição pontual das classes mais vulneráveis deve-se ao método de interpolação utilizado (IDW). No entanto, após testes com outros métodos de interpolação, este se mostrou mais adequado por não desprezar os valores extremos de nível estático, importantes para a adequada atribuição de notas. A interpolação está mais acurada na porção ocidental da área devido ao maior número de dados de nível estático dos poços. 


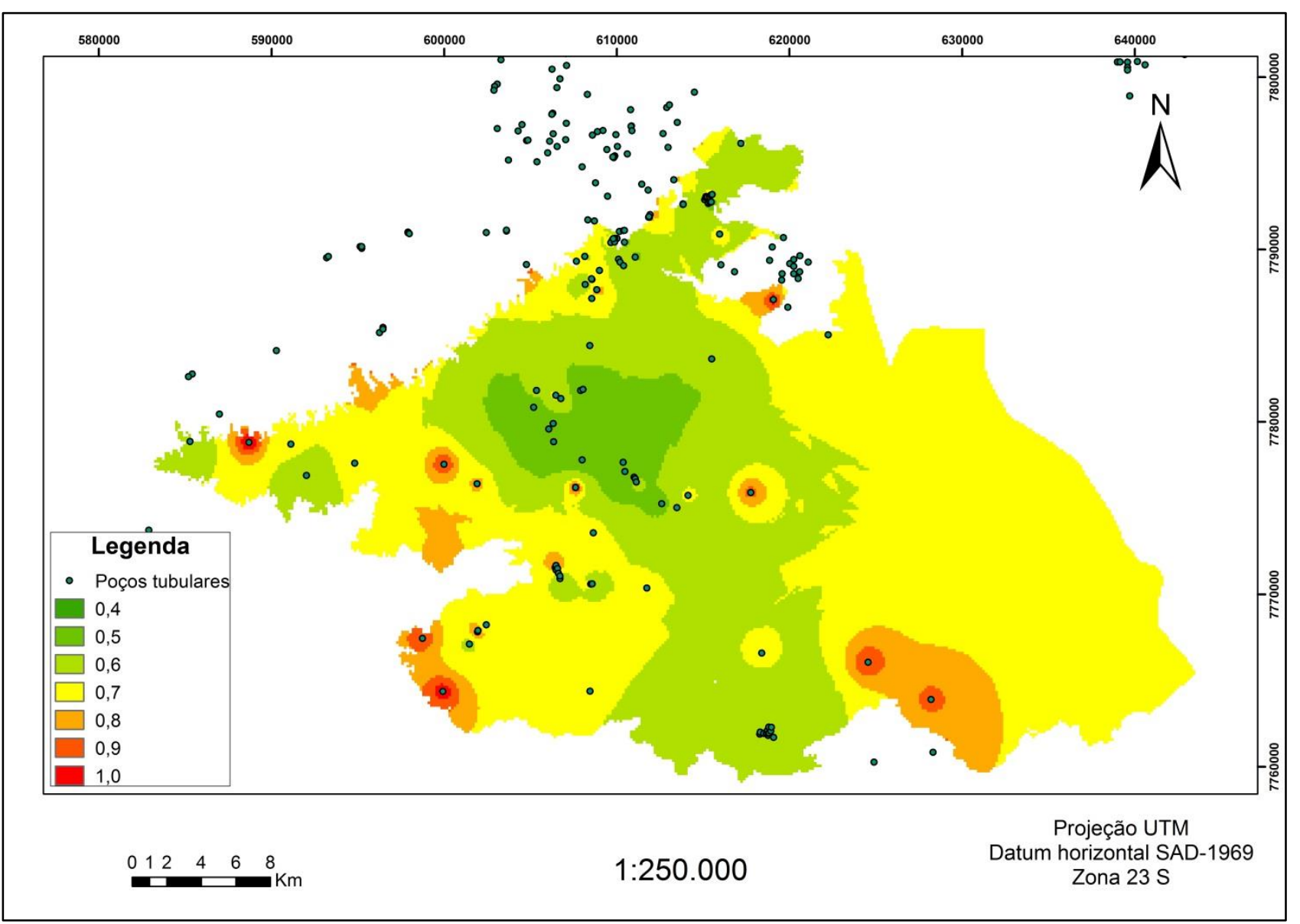

Figura 5 - Mapa de localização dos poços tubulares e notas atribuídas aos níveis freáticos da região de estudo.

\subsection{Potencial de vulnerabilidade}

$\mathrm{O}$ produto dos três mapas (índice GOD) gerou o mapa final de vulnerabilidade à contaminação (Figura 6).

A maior parte da região de estudo apresenta níveis de vulnerabilidade natural baixa. $\mathrm{O}$ nível moderado de vulnerabilidade natural localiza-se, pontualmente, nas regiões central e oeste da área de estudo, ao longo da Serra do Curral, Serra da Moeda e Serra de Itabirito. Na região central o nível moderado pode ser observado pontualmente próximo ao Rio do Peixe, afluente do Rio das Velhas.

As minas e ocorrências de ouro localizam-se principalmente na região oriental da área de estudo onde ocorre o aquífero xistoso que é semi confinado. Essa porção do território, pelo método aplicado, apresenta baixa vulnerabilidade natural.

Embora a vulnerabilidade natural seja baixa, é importante salientar que já foi detectada contaminação por arsênio nas águas superficiais por Borba et al. (2000) nas bacias do Rio das Velhas, Rio do Carmo e Rio Conceição no Quadrilátero Ferrífero. Beato, Monsores \& Bertachinni (2006) destacam o risco de contaminação por drenagem ácida no Sistema aquífero Formação 
Ferrífera e no Sistema aquífero Xistoso do Quadrilátero Ferrífero, visto que já foram detectados valores anômalos de pH nas minas do Faria e Esperança.

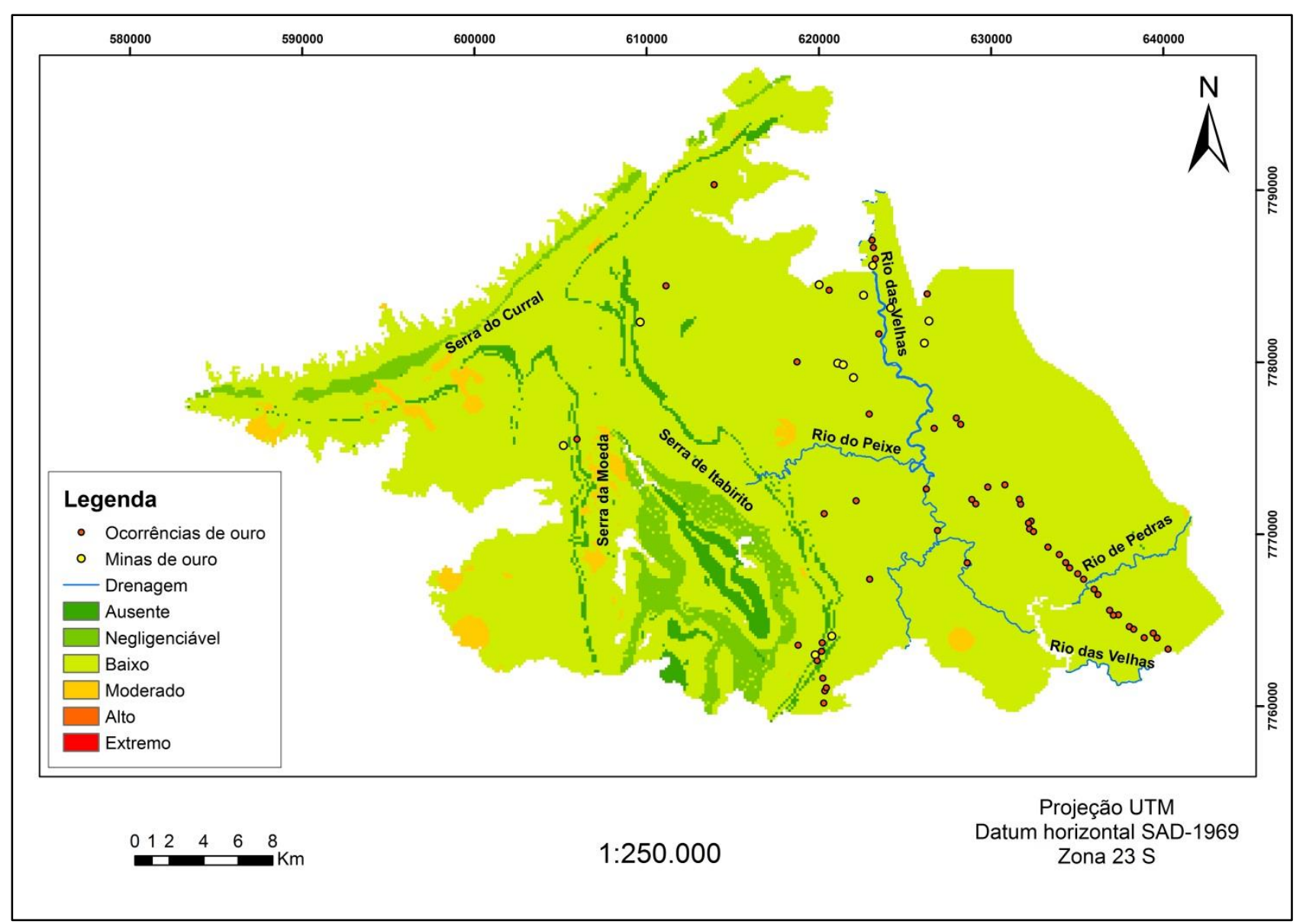

Figura 6 - Mapa de vulnerabilidade natural à contaminação com destaque para as minas de ouro e a rede de drenagem da região de estudo.

\section{CONSIDERAÇÕES FINAIS}

A área de estudo apresenta em sua maior parte, níveis baixos de vulnerabilidade natural à contaminação. Os maiores níveis de vulnerabilidade natural à contaminação foram detectados ao longo das serras do Quadrilátero Ferrífero e pontualmente na região central próximo ao Rio do Peixe.

É necessário maior investimento em sondagens de poços onde há insuficiência de dados a fïm de uma melhor caracterização da área.

A metodologia aplicada mostrou-se adequada, pois permitiu retratar a situação dos aquíferos da região em relação à vulnerabilidade natural e a ocorrência de ouro. 


\section{REFERÊNCIAS}

ABreU, A. T. DE; FARIA, E. M. DE; GUimARÃES, J. A. C.; LEITE, A. DO L.; LENA, J. C. DE. Avaliação em laboratório do uso de sistemas de coberturas alcalinas para prevenção da drenagem ácida de mina. Revista Brasileira de Ciência do Solo, v. 36, p. 787-801, 2012.

BEATO, D. A. C.; MONSORES, A. M.; BERTACHINI, A. C. Potencial aquífero nos metassedimentos do Quadrilátero Ferrífero - Região da APA SUL RMBH - MG. Revista Águas Subterrâneas, Suplemento - XIV Congresso Brasileiro de Águas Subterrâneas (2006). 2006.

BIFANO, M. A.; SOUZA, V. P. DE. Predição do potencial de drenagem ácida de minas, utilizando o método estatístico. In: JORNADA DO PROGRAMA DE CAPACITAÇÃO INTERNA. 1., 2007, Rio de Janeiro. Anais... Rio de Janeiro, 2007.

BORBA, R. P.; FIGUEIREDO, B. R; RAWLINS, B.; MATSCHULLAT, J. Arsenic in water and sediment in the Iron Quadrangle, State of Minas Gerais, Brazil. Revista Brasileira de Geociências, v. 30, p. 558-561, 2000.

CPRM, Serviço Geológico Do Brasil. Geobank. Disponível em: $<$ http://geobank.sa.cprm.gov.br/pls/publico/recmin.recursosminerais.cons_recursos?p_comando=re carrega\&p_webmap $=N \& p \_c o n s u l t a=\& p \_u f=M G \& p \_$municipio $=\& p \_s u b s t a n c i a=\& p \_t o p o n i m i a=\&$ p_latitudeN=\&p_longitudeE=\&p_latitudeS=\&p_longitudeW=>. Acesso em: 12 out. 2014.

CPRM, Serviço Geológico Do Brasil. Siagas. Disponível em:< http://siagasweb.cprm.gov.br/layout/pesquisa_complexa.php>. Acesso em: 13 Maio 2014.

CALIL, P. M.; OlIVEIRA, L. F. C. DE; KLIEMANN, H. J.; OLIVEIRA, V. A. DE. Caracterização geomorfométrica e do uso do solo da Bacia Hidrográfica do Alto Meia Ponte, Goiás. Revista Brasileira de Engenharia Agrícola e Ambiental, v. 16, p. 433-442, 2012.

CAMPANER, V. P.; LUIZ-SILVA, V. Processos físico-químicos em drenagem ácida de mina em mineração de carvão no sul do Brasil. Química Nova, v. 32, n. 1, p. 146-152, 2009.

CPRM, Serviço Geológico Do Brasil. Projeto APA Sul RMBH: hidrogeologia. André Luiz M. Monsores. Belo Horizonte: SEMAD/CPRM, 2005.

CUTRIM, A. O.; CAMPOS, J. E. G. Avaliação da vulnerabilidade e perigo à contaminação do Aquífero Furnas na cidade de Rondonópolis (MT) com aplicação dos métodos GOD e POSH. Geociências, v. 29, p. 401-411, 2010.

DUIJVENBOODEN, W. V.; WAEGENINGH, H.G. V. Vulnerability of Soil and Groundwater to Pollutants, In: INTERNATIONAL CONFERENCE HELD IN THE NETHERLANDS, TNO COMMITTEE ON HYDROLOGICAL RESEARCH, 38., 1987, Netherlands. Proceedings and Information... Netherlands, 1987.

FOSTER, S.; HIRATA, R.; GOMES, D.; D’ELIA, M.; PARIS, M. Groundwater Quality Protection: A Guide for Water Service Companies, Municipal Authorities and Environment Agencies. Washington: Banco Mundial, 2002. 114 p. Traduzido por Silvana Vieira, 2006: Proteção da qualidade da água subterrânea: um guia para empresas de abastecimento de água, órgãos municipais e agências ambientais. 
FRANTZ, L. C. Avaliação do índice de vulnerabilidade do aquífero Guarani no perímetro urbano da cidade de Sant'Ana do Livramento - RS. Santa Maria. 2005. 87f. Dissertação (Mestrado em Engenharia Civil) - Universidade Federal de Santa Maria, 2005.

GONÇALVES, L. R. Vulnerabilidade natural e avaliação de risco de contaminação dos sistemas de aquíferos nas áreas degradadas pela extração de carvão na bacia hidrográfica do rio Mãe Luzia. Porto Alegre. 2012. 80 f. Dissertação (Mestrado em Engenharia) - Universidade Federal do Rio Grande do Sul, 2012.

KREBS, A. S. J.; POSSA, M. V. O papel da hidrogeologia como instrumento de gestão ambiental na mineração de carvão. In: SOARES, P. S. M.; SANTOS, M. D. C. DOS; POSSA, M. V. (ed.). Carvão Brasileiro: Tecnologia e meio ambiente. Rio de Janeiro: CETEM/MCT, 2008. p. 109127.

LiNHARES, F. M.; ALMEIDA, C. DAS N.; SILANS, A. M. B. P. DE; COELHO, V. H. R. Avaliação da vulnerabilidade e do risco à contaminação das águas subterrâneas da bacia hidrográfica do rio Gramame (PB). Sociedade e Natureza, v. 26, p. 139-157, 2014.

MAIA, P. H. P.; CRUZ, M. J. M. Um novo método para avaliar a vulnerabilidade de aquíferos. Brazilian Journal of Aquatic Science and Technology, v. 15, p. 29-40, 2011.

MARTÍNEZ, M. M.; SILVA, J. L. S. DA; LOPES, G. N. Avaliação da vulnerabilidade das águas subterrâneas no Município de Santa Cruz Do Sul, RS/Brasil. Revista Agro@mbiente On-line, v. 2, 2008.

MURADÁS, K.; WOJAHN, D.; COELHO, O. G. W. Levantamento de dados geomorfológicos e hidrogeológicos para mapeamento de vulnerabilidade de contaminação do Aquífero Guarani nos municípios de Portão e Estância Velha/RS utilizando o método DRASTIC. Revista Ambiente \& Água, v. 5, p. 172-194, 2010.

PARANHOS, R. M.; PAIVA J. B. D. DE. Avaliação de metodologia de estimativa de produção de sedimentos em uma pequena bacia rural de encosta. Revista Brasileira de Recursos Hídricos, v. 13, p. 7-18, 2008.

ROESER, H. M. P.; ROESER, P. A. O Quadrilátero Ferrífero - MG, Brasil: aspectos sobre sua história, seus recursos minerais e problemas ambientais relacionados. Geonomos, v. 18, p. 33 - 37 , 2010.

RUCHKYS, U. A. Geoparques e a musealização do território: um estudo sobre o Quadrilátero Ferrífero. Revista do Instituto de Geociências - USP, v. 5, p. 35-46, 2009.

RUCHKYS, U. A; MACHADO, M. M; CASTRO, P. T. A; RENGER, F. E.; TREVISOL, A. Geoparque Quadrilátero Ferrífero, Minas Gerais. In: SHOBBENHAUS, C.; SILVA, C. (Orgs.) Geoparques do Brasil: propostas. Rio de Janeiro: Serviço Geológico do Brasil, 2012. p. 183- 220.

RUCHKYS, U. A.; MACHADO, M. M. M. Patrimônio geológico e mineiro do Quadrilátero Ferrífero, Minas Gerais - caracterização e iniciativas de uso para educação e geoturismo. Boletim Paranaense de Geociências, v. 70, p. 120-136, 2013.

TAVARES, P. R. L.; CASTRO, M. A. H. DE; COSTA, C. T. F. DA; SILVEIRA, J. DAS G. P. DA; ALMEIDA-JÚNIOR, F. J. B. DE. Mapeamento da vulnerabilidade à contaminação das águas 
subterrâneas localizadas na Bacia Sedimentar do Araripe, Estado do Ceará, Brasil. REM: Revista Escola de Minas, v. 62, p. 227-236, 2009.

VILLAR, P. C.; RIBEIRO, W. C. Sociedade e gestão do risco: o Aquífero Guarani em Ribeirão Preto-SP, Brasil. Revista de Geografía Norte Grande, v. 43, p. 51-64, 2009.

ZANETTI, S. S.; SILVA, J. M. A. DA; SOUSA, E. F.; OLIVEIRA, V. DE P. S. DE; ALMEIDA, F. T. DE. Modelagem hidrológica em microbacia hidrográfica Parte I: aprimoramento do modelo HidroBacia. Revista Brasileira de Engenharia Agrícola e Ambiental, v. 13, p. 429-434, 2009.

Trabalho enviado em 29/09/2016 Trabalho aceito em 06/12/2016 